\title{
Overview of Thermoelectric Generation for Hybrid Vehicles
}

\author{
Xiaodong Zhang ${ }^{1}$, K. T. Chau ${ }^{2}$, and C. C. Chan ${ }^{3}$ \\ ${ }^{1}$ Department of Electrical and Electronic Engineering, University of Hong Kong, xiaodong@eee.hku.hk \\ ${ }^{2}$ Department of Electrical and Electronic Engineering, University of Hong Kong, ktchau@eee.hku.hk \\ ${ }^{3}$ Department of Electrical and Electronic Engineering, University of Hong Kong, ccchan@eee.hku.hk
}

\begin{abstract}
With ever increasing concern on oil prices and energy conservation, there is a fast growing interest in hybrid vehicles globally. Currently, all hybrid vehicles, including micro, mild and full hybrids, adopt internal combustion engines which are inefficient in general. The corresponding waste heat of exhaust gas constitutes up to $40 \%$ of the fuel consumption. So, it is a pressing need for researchers to develop viable energy-efficient technology to recover the waste energy of exhaust gas for hybrid vehicles. In this paper, an overview of thermoelectric waste-heat energy recovery for hybrid vehicles is presented, with emphasis on the system configuration, heat exchanger, thermoelectric material, power converter and maximum power point tracking.
\end{abstract}

\section{Keywords}

energy recovery, exhaust gas, hybrid vehicles, thermoelectric generation, waste heat

\section{INTRODUCTION}

The oil consumption of road transportation is one of the major issues in the world, especially in the field of energy and environment. Particularly, the oil consumption and carbon dioxide emission from road transportation in China have exhibited a dramatic growth. The latest statistics indicates that the annual oil demand in China will reach 407 million tons by 2010, while the road transportation will account for $54.1 \%$ of the total demand [Xinhua, 2008]. So, just a $1 \%$ improvement in the fuel economy of automobiles will save about 2 million tons of oil in China, and much more in the world. Internal combustion engine vehicles (ICEVs) have been developed for over 120 years. Nevertheless, their energy efficiency has not been greatly improved from the original version. Actually, for modern gasoline fueled ICEVs as shown in Figure 1, there is only about 25\% of the fuel combustion energy is utilized for vehicle operation whereas about $40 \%$ is lost in the form of waste heat of exhaust gas [Stabler, 2002].

Among various classes of electric vehicles (EVs), including the battery EV, hybrid EV and fuel cell EV, the hybrid EV (HEV) incorporates both engine and motor [Chan and Chau, 2001], and adopts a hybridization of two energy sources (gasoline fuel and battery) [Chau and Wong, 2001]. Since HEVs, loosely termed hybrid vehicles, take the definite advantage of high fuel economy, they are becoming attractive in the auto market, [Chau and Wong, 2002; Ehsani et al., 2005; Wong et al., 2006]. In order to enhance their competitiveness, there is a pressing need to develop various energy-efficient technologies for HEVs [Chau and Chan, 2007], including both energy generation and energy utilization. A recent study has revealed that the fuel economy of ICEVs can be increased by up to $20 \%$ simply by capturing the waste heat of exhaust gas and converting about $10 \%$ of it to electricity [Yang, 2005]. Hence, for HEVs, the recovered energy can be easily stored in the battery or directly used by automotive electronic appliances. The significance and value of waste heat energy recovery for HEVs is tremendous. The benefits will not only be the improvement in fuel economy, but also the conservation of energy resource and hence the protection of environment [Wong et al., 2005].

Thermoelectric generation (TEG) has the ability to directly recover such waste heat and generate electricity without adding engine load [Rowe, 1999]. So, the purpose of this paper is to give an overview of latest TEG technology for hybrid vehicles.

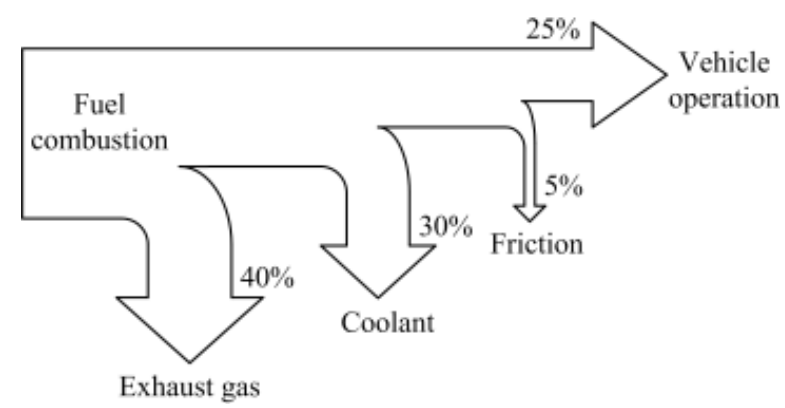

Fig. 1 Consumption of fuel combustion

\section{SYSTEM CONFIGURATION}

The thermoelectric effects are the direct conversion of 
heat differentials to electric voltage and vice versa [Rowe, 2006]. The Seebeck effect is the conversion of temperature differences directly into electricity. This effect was first discovered by Thomas Johann Seebeck in 1821, who found that a voltage existed between two ends of a metal bar when a temperature gradient existed in the bar. In contrast, the Peltier effect was first observed in 1834 by Jean Peltier, who found the reverse of the Seebeck effect. Based on the Seebeck effect, the TEG system takes the advantages of no moving parts, silent operation and very reliable. For HEVs, the waste exhaust heat can be recovered directly to electrical energy for battery charging, thereby increasing the overall vehicle fuel efficiency.

Figure 2 shows a typical temperature distribution of the exhaust gas system, in which it is composed of the exhaust manifold, exhaust pipe, catalytic converter, center muffler and rear muffler [LaGrandeur et al., 2005]. It is a natural choice that the heat exchanger should be installed at the location with the highest temperature, namely at the front-end location. Since the corresponding temperature at full load is up to $790^{\circ} \mathrm{C}$, it may exceed the allowable working temperatures of the selected thermoelectric materials. As a result, a compromise may be required on the selection of heat exchanger location. The heat energy available from exhaust gas needs to be extracted by the heat exchanger. The heat exchanger can directly combine with the thermoelectric devices to

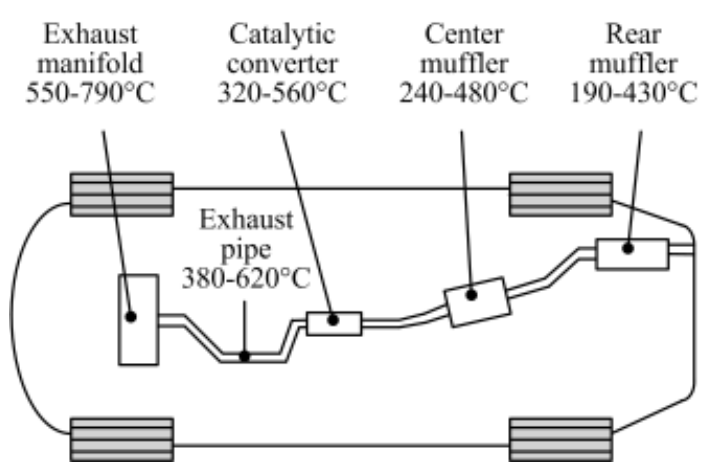

Fig. 2 Temperature distribution of exhaust gas

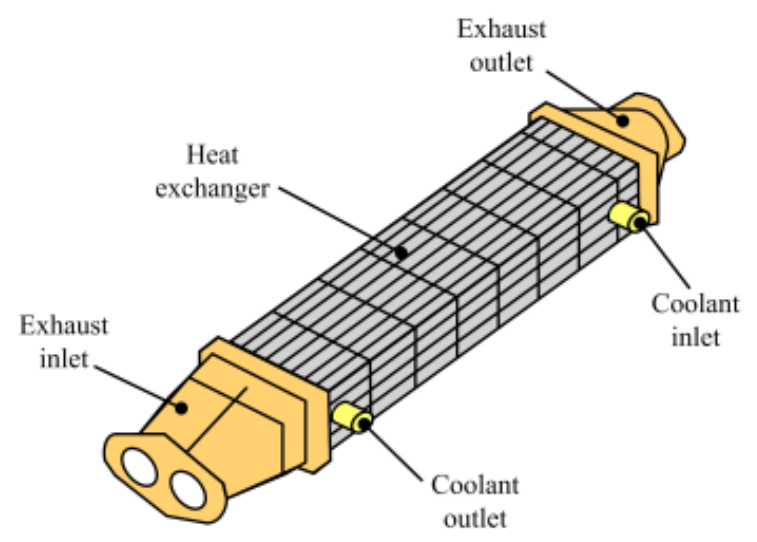

Fig. 3 Heat exchanger form a united system, hence offering a compact structure [Matsubara, 2002]. Alternatively, the heat exchanger shown in Figure 3 works with the thermoelectric devices by means of a pump which circulates the working fluid (for example, 75\% $\mathrm{He}$ and $25 \% \mathrm{Xe}$ ) between them [LaGrandeur et al., 2006]. The use of this pumping loop can allow for a wide variation of exhaust gas flow and hence thermal flux. It should be noted that the design of heat exchanger involves a trade-off between the thermal exchange efficiency and the exhaust gas flow rate. The restriction of the flow path of exhaust gas for the improvement of thermal exchange efficiency may result in the generation of exhaust backpressures which will reduce the engine efficiency and hence offset the overall energy efficiency.

\section{TEG MATERIAL}

The selected thermoelectric material needs to offer high energy conversion efficiency which is measured by the figure of merit:

$$
Z T=\frac{S^{2} T}{\kappa \rho}
$$

where $S$ is the thermoelectric power, $T$ is the absolute temperature, $\kappa$ is the total thermal conductivity and $\rho$ is the electrical resistance [Yang, 2005]. In recent years, the characteristics of thermoelectric materials have been significantly improved in terms of both the highest ZT value and the temperature range. Figure 4 and Figure 5 show the ZT characteristics of typical thermoelectric materials [Crane and Bell, 2006; Caillat et al., 2001]. It can be seen that both the p-type and n-type $\mathrm{Bi}_{2} \mathrm{Te}_{3}$ offer the optimal $Z T$ values at the lower temperature range $\left(<200^{\circ} \mathrm{C}\right)$ of exhaust gas; the p-type Te-Ag-Ge-Sb alloy (TAGS) and the n-type PbTe offer the optimal ZT values at the medium temperature range $\left(200-500^{\circ} \mathrm{C}\right)$; and the skutterudites ( $\mathrm{p}$-type $\mathrm{CeFe}_{4} \mathrm{Sb}_{12}$ and n-type $\mathrm{CoSb}_{3}$ ) offer the optimal $Z T$ values at the higher temperature range $\left(500-800^{\circ} \mathrm{C}\right)$.

In order to achieve the highest average ZT over the entire operating temperature range of exhaust gas, different thermoelectric elements can be employed. To manage the thermoelectric compatibility both within each element and between individual elements, each material segment and layer may have different thicknesses [Rowe, 2006]. In a traditional TEG system, as shown in Figure 6, the configuration suffers from a problem for the elements with different thicknesses and different thermal expansion coefficients. Recently, an alternative configuration as shown in Figure 7 has been proposed, which can accommodate elements of different thicknesses and thermal expansion coefficients [LaGrandeur et al., 2006; Bell, 2004]. 


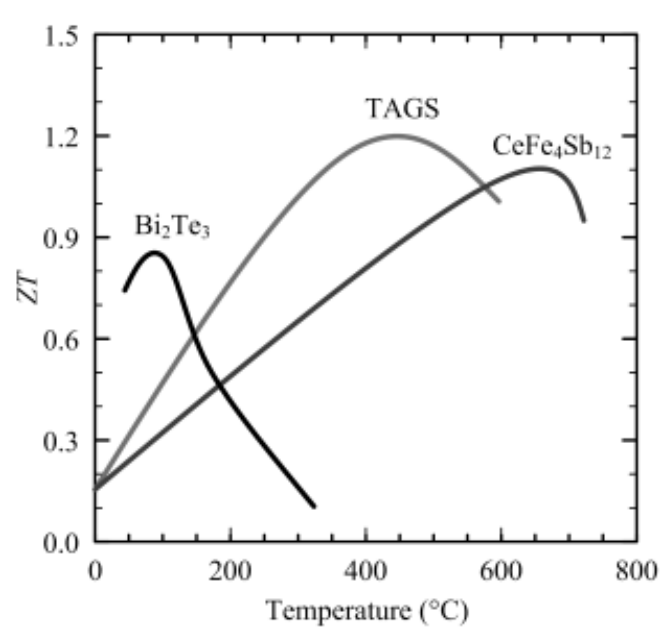

Fig. 4 Comparison of TEG p-type materials

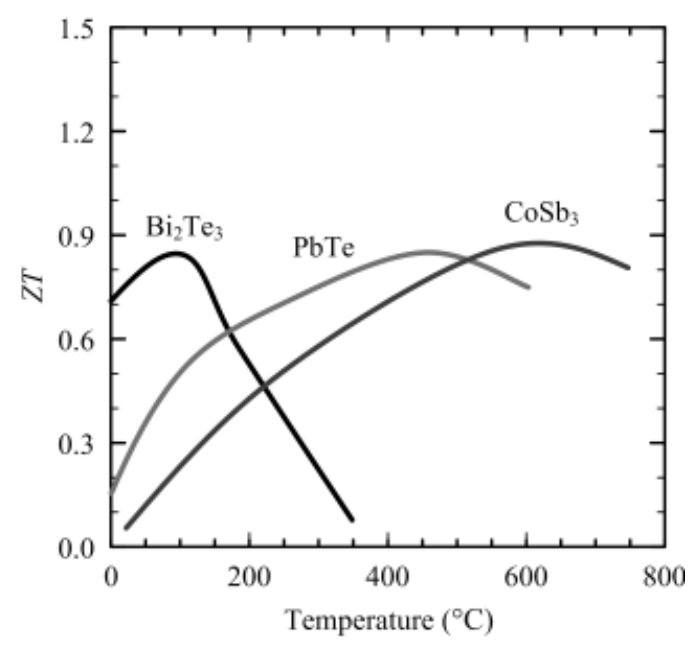

Fig. 5 Comparison of TEG n-type materials

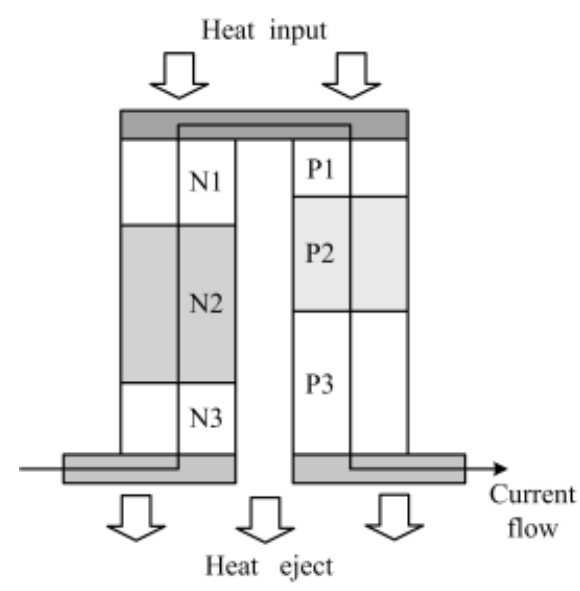

Fig. 6 Traditional TEG configuration

\section{TEG CONVERTER}

The TEG system needs to charge the battery or supply electrical energy to the vehicle power network. Since

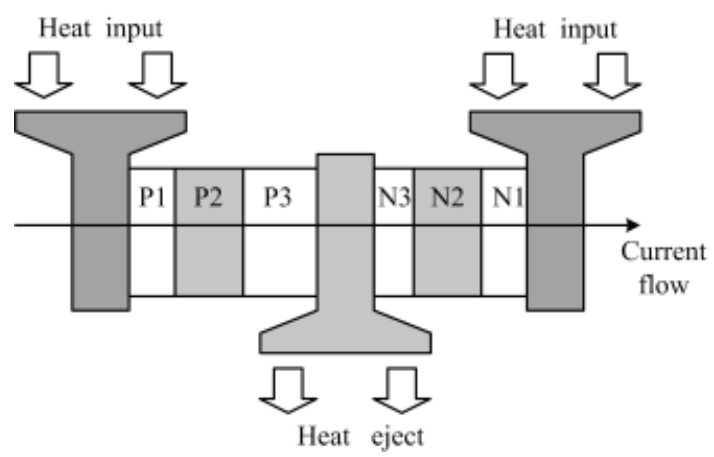

Fig. 7 Alternative TEG configuration

the TEG output voltage changes dynamically with the temperature of exhaust gas and hence varies in a wide range, power conditioning between the TEG and the load is inevitable as shown in Figure 8. For example, the output voltage range of typical TEG is $0-25 \mathrm{~V}$, which needs to be converted to 12.3-16.5 V for battery charging [Kim and Lai, 2008]. Therefore, a dc-dc converter, having step-up and step-down characteristics, is required to serve for power conditioning.

Several dc-dc converter topologies have been proposed for TEG conversion, such as the SEPIC converter [Eakburanawat and Boonyaroonate, 2006], the Ćuk converter [Yu et al., 2007] and the boost-buck cascade converter [Kim and Lai, 2007]. As shown in Figure 9, the SEPIC converter takes the advantages of low-ripple input current which is desirable for TEG operation, and wide-range output voltage which is essential for battery charging. Additionally, as shown in Figure 10, the Ćuk converter takes the advantage of low ripple currents at both the input and the output, though with the inconvenience of inverting output voltage. However, both converters suffer from high component stresses, and thus not favorable for high power applications. On the other hand, as shown in Figure 11, the boost-buck cascade converter is a two-stage power circuit which adopts three-phase interleaving technique to reduce total current ripple and synchronous rectification to reduce conduction loss. However, this converter requires more power devices and components, thus increasing the hardware cost and control complexity.

\section{MAXIMUM POWER POINT TRACKING}

In order to fully utilize the thermoelectric material and maximize the recovery of waste heat energy, the TEG needs to adopt the maximum power point tracking (MPPT). The MPPT methods that have been applied to TEG are mostly developed for photovoltaic generation, such as the load matching method [Khouzam, 1990], the curve-fitting technique [Kislovski and Redl, 1994], the incremental conductance method [Kuo et al., 2001], 
the ripple correlation method [Shmilovitz, 2005] and the perturbation and observation (P\&O) method [Femia et al., 2005]. Moreover, the fuzzy logic [Veerachary et al., 2003] and neural network [D’Souza et al., 2005] have also been adopted to improve the MPPT for photovoltaic generation.

Among the aforementioned MPPT methods, the P\&O method is most commonly adopted. The online tuning for MPPT control can be explained by Figure 12. When the converter is initialized to work with a duty cycle $\delta_{0}$, there are two possible initial operating points, either $\mathrm{A}$ or $\mathrm{B}$, denoting the output power $P_{0}$. Then, after a positive perturbation of duty cycle $\Delta \delta$ is applied, the new output power $P_{1}$ will be observed. If $P_{1}$ is greater than $P_{0}$, it indicates that the initial operating point is $\mathrm{A}$, thus the duty cycle $\delta$ should keep on increasing in the next iteration to move the operating point towards $P_{\max }$. On the contrary, if $P_{1}$ is smaller than $P_{0}$, it reveals that the initial operating point is $\mathrm{B}$. Thus, the sign of $\Delta \delta$ should be reversed so as to reduce $\delta$ to achieve a larger output power in the next iteration. By repeating this process, the system will operate at steady state around the maxi-

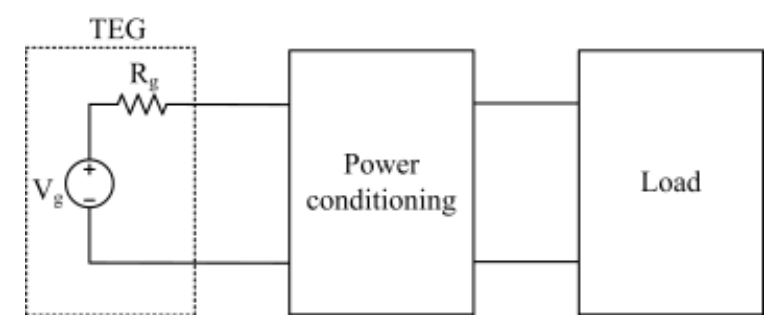

mum power point automatically.

It should be noted that this MPPT method has the selfsearching ability, which can overcome parameter variations and uncertainties. Nevertheless, the corresponding convergence and searching time are not well defined.

\section{CONCLUSION}

In this paper, the TEG technology of waste-heat energy recovery for hybrid vehicles has been overseen. Particularly, the TEG materials and their configurations as well as the TEG converters and their MPPT methods have been discussed in detail. It is anticipated that this emerging technology will be a major research direction for HEVs in near future, and will push the energy efficiency of HEVs to a new height.

\section{Acknowledgements}

This work is supported and funded by the University of Hong Kong.

\section{References}

Bell, L. E., High Power Density Thermoelectric Systems, Proceedings of International Conference on Thermoelectrics, 1-5, 2004.

Caillat, T., J. P. Fleurial, G. J. Snyder, and A. Borshchevsky, Development of High Efficiency Segmented Thermoelectric Unicouples, Proceedings of International Conference on Thermoelectrics, 282285, 2001.

Chan, C. C., and K. T. Chau, Modern Electric Vehicle

Fig. 8 TEG power conditioning

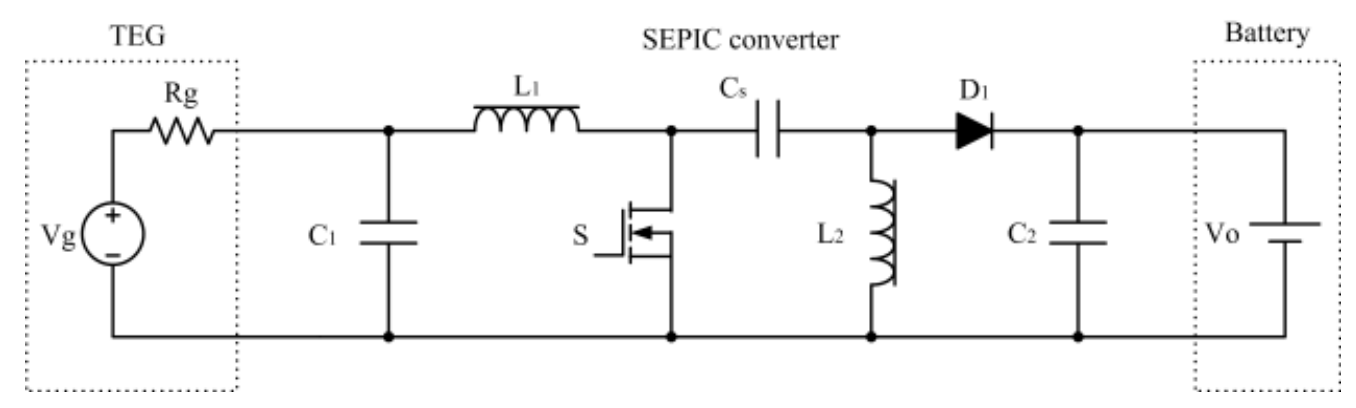

Fig. 9 TEG SEPIC converter

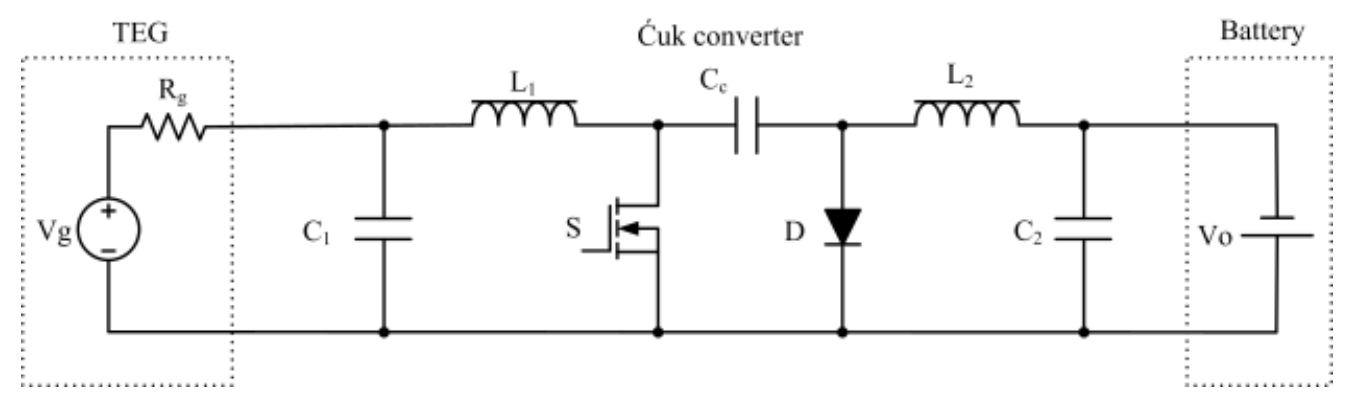

Fig. 10 TEG Ćuk converter 


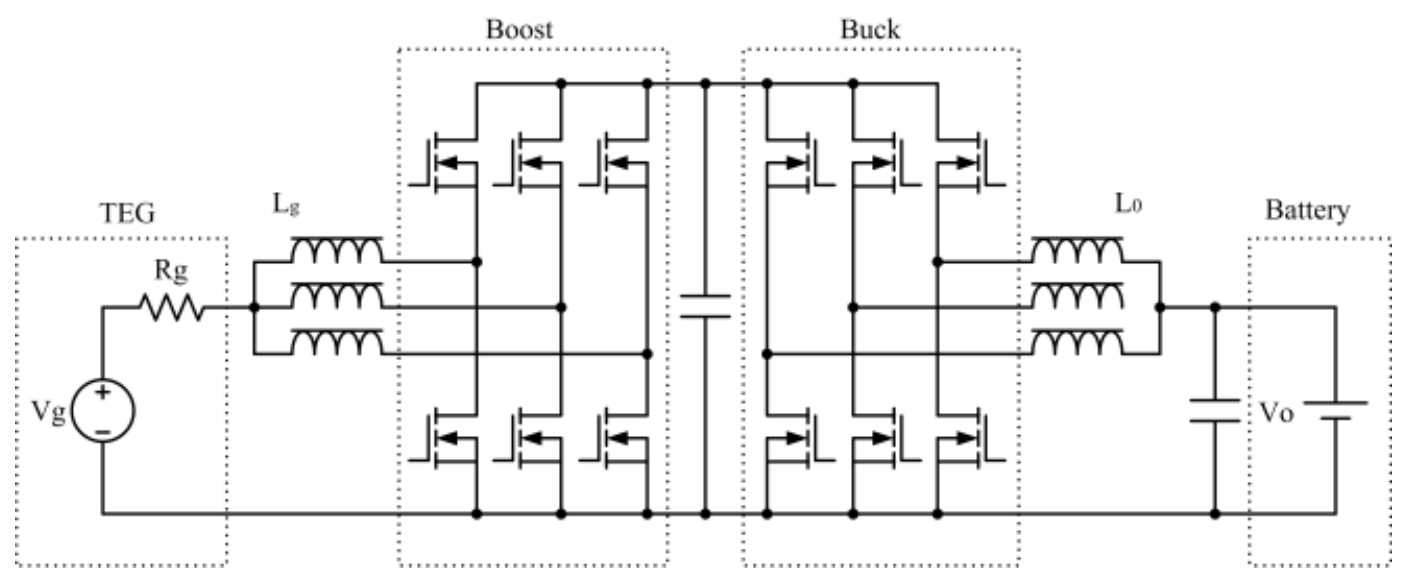

Fig. 11 TEG boost-buck cascade converter

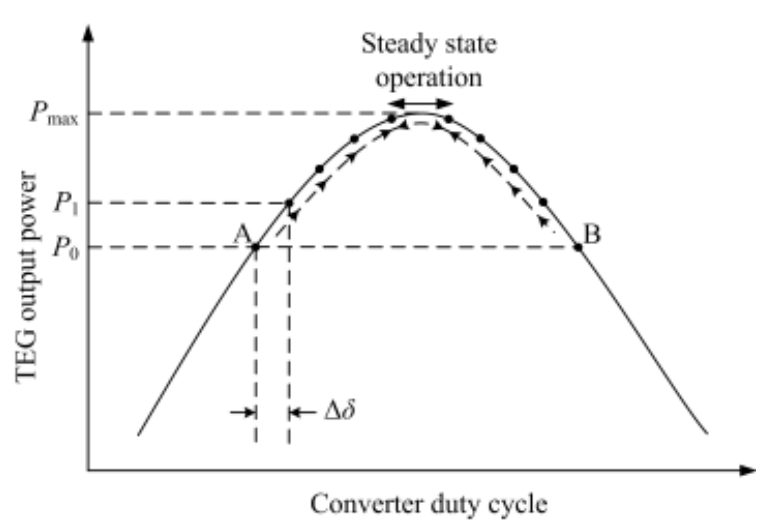

Fig. 12 MPPT control

Technology, Oxford University Press, 2001.

Chau, K. T., and C. C. Chan, Emerging Energy-Efficient Technologies for Hybrid Electric Vehicles, Proceedings of IEEE, Vol. 95, No. 4, 821-835, 2007.

Chau, K. T., and Y. S. Wong, Hybridization of Energy Sources in Electric Vehicles, Energy Conversion and Management, Vol. 42, No. 9, 1059-1069, 2001.

Chau, K. T., and Y. S. Wong, Overview of Power Management in Hybrid Electric Vehicles, Energy Conversion and Management, Vol. 43, No. 15, 19531968, 2002.

Crane, D., and L. E. Bell, Progress Towards Maximizing the Performance of a Thermoelectric Power Generator, Proceedings of International Conference on Thermoelectrics, No. II-1, 1-6, 2006.

D’Souza, N. S., L. A. C. Lopes, and X. Liu, An Intelligent Maximum Power Point Tracker Using Peak Current Control, Proceedings of IEEE Power Electronics Specialists Conference, 172-177, 2005.

Eakburanawat, J., and I. Boonyaroonate, Development of a Thermoelectric Battery - Charger with Microcontroller - Based Maximum Power Point Tracking Technique, Applied Energy, Vol. 83, No. 7, 687-704, 2006.
Ehsani, M., Y. Gao, S. E. Gay, and A. Emadi, Modern Electric, Hybrid Electric, and Fuel Cell Vehicles: Fundamentals, Theory, and Design, CRC Press, 2005.

Femia, N., G. Petrone, G. Spagnuolo, and M. Vitelli, Optimization of Perturb and Observe Maximum Power Point Tracking Method, IEEE Transactions on Power Electronics, Vol. 20, No. 4, 963-973, 2005.

Khouzam, K., Optimum Load Matching in DirectCoupled Photovoltaic Power Systems - Application to Resistive Loads, IEEE Transactions on Energy Conversion, Vol. 5, No. 2, 265-271, 1990.

Kim, R. Y., and J. S. Lai, A Seamless Mode Transfer Maximum Power Point Tracking Controller for Thermoelectric Generator Applications, Proceedings of IEEE IAS Annual Meeting, 977-984, 2007.

Kim, R. Y., and J. S. Lai, Aggregated Modeling and Control of a Boost - Buck Cascade Converter for Maximum Power Point Tracking of a Thermoelectric Generator, Proceedings of IEEE Applied Power Electronics Conference and Exposition, 1754 -1760, 2008.

Kislovski, A., and R. Redl, Maximum - Power - Tracking Using Positive Feedback, Proceedings of IEEE Power Electronics Specialists Conference, 10651068, 1994.

Kuo, Y. C., T. J. Liang, and J. F. Chen, Novel Maximum - Power - Point Tracking Controller for Photovoltaic Energy Conversion System, IEEE Transactions on Industrial Electronics, Vol. 48, No. 3, 594-601, 2001.

LaGrandeur, J., D. Crane, and A. Eder, Vehicle Fuel Economy Improvement Through Thermoelectric Waste Heat Recovery, Proceedings of Diesel Engine Emissions Reduction Conference, 1-7, 2005.

LaGrandeur, J., D. Crane, S. Hung, B. Mazar, and A. Eder, Automotive Waste Heat Conversion to Electric Power Using Skutterudite, TAGS, PbTe and BiTe, Proceedings of International Conference on 
Thermoelectrics, No. B10-2, 1-6, 2006.

Matsubara, K., Development of a High Efficient Thermoelectric Stack for a Waste Exhaust Heat Recovery of Vehicles, Proceedings of International Conference on Thermoelectrics, 418-423, 2002.

Rowe, D. M., Thermoelectrics Handbook: Macro to Nano, CRC/Taylor \& Francis, 2006.

Rowe, D. M., Thermoelectrics, an Environmentally Friendly Source of Electrical Power, Renewable Energy, Vol. 16, No. 1-4, 1251-1256, 1999.

Shmilovitz, D., On the Control of Photovoltaic Maximum Power Point Tracker via Output Parameters, IEE Proceedings - Electric Power Applications, Vol. 152, No. 2, 239-248, 2005.

Stabler, F., Automotive Applications of High Efficiency Thermoelectrics, Proceedings of DARPA / ONR / DOE High Efficiency Thermoelectric Workshop, 126, 2002.

Veerachary, M., T. Senjyu, and K. Uezato, Neural - Network - Based Maximum - Power - Point Tracking of Coupled - Inductor Interleaved - Boost Converter Supplied PV System Using Fuzzy Controller, IEEE Transactions on Industrial Electronics, Vol. 50, No. 4, 749-758, 2003.

Wong, Y. S., K. T. Chau, and C. C. Chan, Battery Sizing for Plug-In Hybrid Electric Vehicles, Journal of Asian Electric Vehicles, Vol. 4, No. 2, 899 - 904, 2006.

Wong, Y. S., K. T. Chau, and C. C. Chan, Load Forecasting of Hybrid Electric Vehicles under Real Time Pricing, Journal of Asian Electric Vehicles, Vol. 3, No. 2, 815 - 818, 2005

Xinhua, China's Oil Consumption to Hit 563M Tons in 2020, Chinadaily.com.cn, 2008.

Yang, J., Potential Applications of Thermoelectric Waste Heat Recovery in the Automotive Industry, Proceedings of International Conference on Thermoelectrics, 170-174, 2005.

Yu, C., K. T. Chau, and C. C. Chan, Thermoelectric Waste - Heat Energy Recovery for Hybrid Electric Vehicles, Proceedings of 23rd International Electric Vehicle Symposium, CD-Rom, 2007.

(Received May 19, 2008; accepted August 2, 2008) 